Supplement of The Cryosphere, 12, 3813-3825, 2018

https://doi.org/10.5194/tc-12-3813-2018-supplement

C Author(s) 2018. This work is distributed under

the Creative Commons Attribution 4.0 License.

(c) (1)

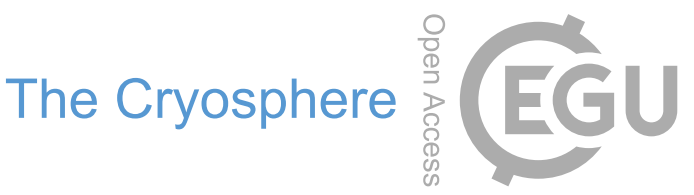

Supplement of

\title{
Seasonal to decadal variability in ice discharge from the Greenland Ice Sheet
}

Michalea D. King et al.

Correspondence to: Michalea D. King (michaleaking@gmail.com)

The copyright of individual parts of the supplement might differ from the CC BY 4.0 License. 


\section{Supplementary Material}

\section{S.1 Glacier Flux Gates}

A flux gate transect is partitioned into equally-spaced bins approximately $250 \mathrm{~m}$ in width. Transects are sampled at a higher spatial resolution for small glaciers $(<4 \mathrm{~km}$ wide), and in cases where increased sampling improves the quality of surface

5 elevation data extraction and processing. Ice surface velocity is assumed to be representative of the depth-averaged velocity.
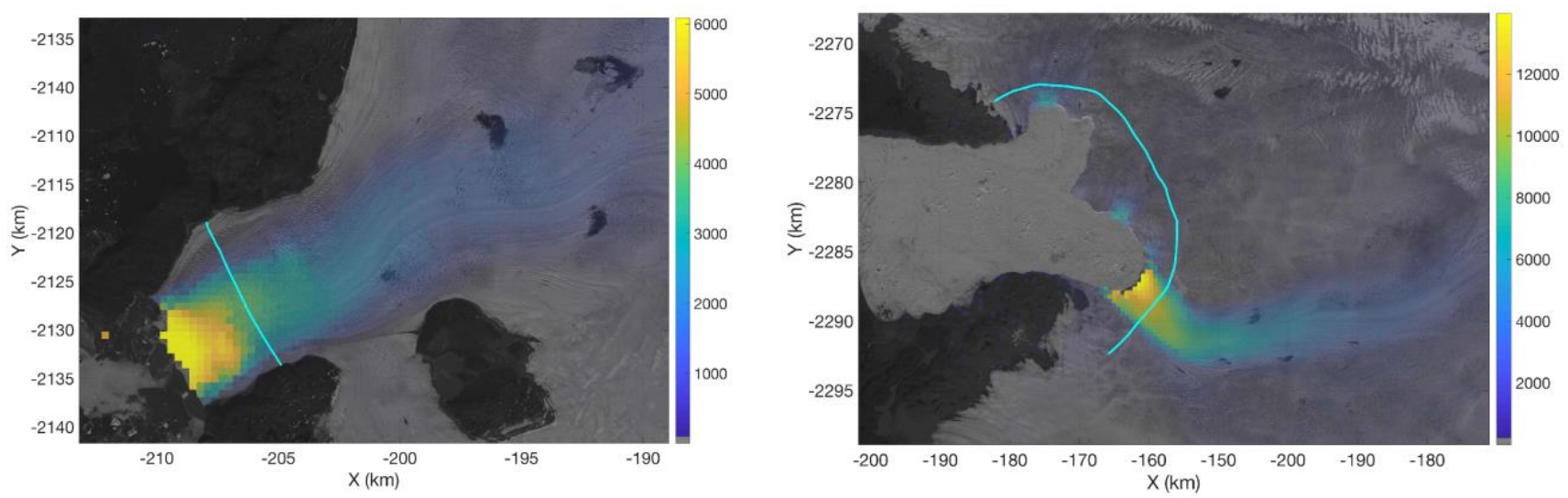

Figure S1: Examples of glacier flux gates (teal) drawn for Store Glacier (left) and Jakobshavn Glacier (right). Underlying scenes depict orthorectified optical imagery of the glacier termini with an overlying velocity map of ice speeds in July 2016 , expressed as $\mathbf{m ~ a}^{-1}$.

\section{S.2 Glacier Velocity}

Observations of glacier speed are derived from horizontal velocity maps generated using orthorectified optical imagery from LANDSAT 7, LANDSAT 8, and Advanced Spaceborne Thermal Emission and Reflection radiometer (ASTER) bands 1-3 using algorithms described in Jeong et al. (2017). Temporal density is improved by integrating cross-sensor, same-track and

15 cross-path image pairs. Optical observations are augmented by InSAR observations, obtained from the Terra/TandemSAR-X satellite, which become available in 2009. Velocity data, extracted along the multiple coordinate points along the glacier flux gate, are initially filtered by the magnitude of the observational error and the corresponding matching ratio parameter. Errors in the optical observations are a product of the optical imagery quality (noise to pixel ratio), coregistration quality between the paired images, and the velocity of the observed glacier. High signal to noise ratios are common over slow flowing

20 glaciers. We used a minimum matching ratio threshold of 0.0675 (4 out of 64 successfully matched image pairs), excluding 
observations with a matching ratio below this threshold from the analysis. Addition observations are removed if their observational errors are excessively large and dominate the variance of the time series. Here, individual observations with errors that exceed three times the standard deviation of the glacier time series are removed. The resulting time series, with outliers removed, may still consist of thousands of observational data points due to the high density of cross-sensor, cross-

5 track optical observations. These series are then smoothed by a running weekly mean filter, weighted by the magnitude of the observational errors.

Despite the high density of optical velocity data, gaps in the time series still exist during winter months when radar-derived glacier speeds are unavailable. A Kalman Filter, a method that has previously been used to estimate height changes in

10 Antarctica from ICESat data (Nguyen et al. 2005), is applied to model reasonable estimates of glacier speed for these missing periods. Modeled ice velocities for missing months are estimated using a linear model of estimated median acceleration for the specific month of interest, derived using a constructed standard seasonality specific to each glacier. To derive the standard seasonality curve, a weighted moving mean filter, weighted by the uncertainties of the respective observations, is first applied to the time series. Next, any existing secular trends in the monthly-resolved time series are

15 removed by subtracting an up to fourth-order polynomial fit from the data, with the polynomial order selected based off a minimum RMSE. Observations in the resulting detrended series are then grouped into bins by month of observation. The standard expected seasonality for each glacier is derived by finding the median value and covariance of each monthly grouping, including months with observations for a minimum of 5 years throughout the time series. Months with fewer available observations will therefore tend to have a higher range of uncertainty. If, throughout the time series, no optical or

20 radar data exist for a particular month, a standard monthly value is estimated by extracting the desired monthly solution from a periodic function fit to the available monthly median values.

The curve is standardized to produce a modeled seasonality of expected incremental change in speed from one particular month to the next. Within the Kalman filter framework, estimates for missing periods are derived by calculating the 25 optimally-interpolated estimate from the two nearest surrounding observations. With the linear model serving as the initial background state, subsequent analyses are performed at each missing monthly time step by using the values and errors of the two nearest available observations to construct the Kalman gain matrix, W, in Eq. (S1). The Kalman gain is used to appropriately weight the observational innovation, or difference between observations $\left(\mathrm{y}_{1}{ }^{o} \mathrm{y}_{2}{ }^{o}\right)$ and background values at those points $\left(\mathrm{y}_{1}{ }^{b} \mathrm{y}_{2}{ }^{b}\right)$ to produce the analysis at time $\left(t_{i}\right)$ as shown in Eq. (S2). Analysis errors $\left(e_{i}{ }^{a}\right)$ are similarly derived. The

30 subsequent forecast $x_{i+1}^{b}$ (and forecast variance $\sigma_{b+l^{2}}$ ) is computed using the product of the linear model for the month of interest, $\mathbf{M}$, and the analysis, $x_{i}{ }^{a}$ (analysis variance, $\sigma_{a, i}{ }^{2}$ ), plus a random model error component, $\varepsilon_{M}$ (model variance $\sigma_{M 2}$ ). This forecast becomes the new background state at the next time step, $t_{i+1}$. The resulting modeled monthly estimates of glacier velocity are appended to the periods of the time series where observational velocity data are available. 
$\mathbf{W}_{i}=\frac{\left(\mathbf{B}^{o}+\mathbf{R}\right)^{-\mathbf{1}}}{\mathbf{b}_{i}}$

Equation S1: Kalman Gain, W, where denotes $B^{o}$ denotes the background error covariance matrix, $R$ the observational covariance matrix of the two respective observed values used in the analysis, and $b_{i}$ as the vector projection of the background error in the 5 observational space onto the model space (midpoint of the missing month requiring analysis).

$x_{i}^{a}=x_{i}^{b}+w_{i 1}\left(y_{1}^{o}-y_{1}^{b}\right)+w_{i 2}\left(y_{2}^{o}-y_{2}^{b}\right)$
$e_{i}^{a}=e_{i}^{b}+w_{i 1}\left(e_{1}^{o}-e_{1}^{b o}\right)+w_{i 2}\left(e_{2}^{o}-e_{2}^{b o}\right)$

Equation S2: Calculation of the analysis and analysis error at step $i$.

10

$x_{i+1}^{b}=\mathbf{M}\left(t_{i}\right) x_{i}^{a}+\varepsilon_{M}$

$\sigma_{b, i+1}^{2}=\mathbf{M}^{2}\left(t_{i}\right) \sigma_{a, i}^{2}+\sigma_{M}^{2}$

Equation S3: Forecast and forecast variance, which will serve as the background state in the following analysis $(i+1)$.

\section{S.3 Glacier Thickness}

Seasonal acceleration of glaciers is often accompanied by dynamical thinning (Pritchard et al. 2009), which can dampen the seasonal increase in $D$. Although dynamic ice thickness changes are less pronounced than changes in glacier speed, subannual changes in ice thickness are resolvable for many of the glaciers sampled. These sub-annual observations of glacier ice thicknesses along the flux gate are also integrated into the discharge time series calculations. We find glacier thickness

20 across the flux gate by differencing surface elevation data with a glacial bed topography product, BedMachine version 3 (Morlighem et al. 2017), which implements a mass conservation approach based on assimilated available ice thickness and seafloor bathymetry data. Surface elevation data along the glacier transects are extracted from ASTER digital elevation models (DEM's), ArcticDEM (www.arcticdem.org) and SPOT-5 DEM's (Korona et al. 2009), where available.

25 Transects of surface elevation are often noisy and prone to erroneous values. Surface elevations at each timestep are first compared to the GIMP DEM (Howat et al. 2014) values, for a first-pass identification of clear outliers. If, at each observational time, there is valid data for at least $25 \%$ of the bins across the flux gate, the data at the time step is passed along for additional filtering and smoothing (Figure S2). Typically, median ice thicknesses across a glacier flux gate follow a semi-smooth curve which increases in thickness toward the centerline. A 3-5 year median surface elevation transect and

30 variance over the 3-5 year window are used to remove noisy, erroneous elevation data by filtering values that fall more than 
two standard deviations outside the median transect geometry. The temporal range of this window can be increased with consideration to the extent of data sparsity that exists for some glaciers. The bin-dependent z-scores of the remaining, valid data are used to fill missing data along the transect. For example, if the mean z-score of the available surface elevation data at a particular time are found to fall one standard deviation below the 5-year median, values for bins with missing data along

5 the transect would be estimated by subtracting one standard deviation from each specific bin's 3-5 year median elevation. This approach allows for the magnitude of cross-transect variability to be resolved if differential thinning patterns are present, such as more pronounced dynamic thinning near the centerline. The final ice thickness values derived from subtracting bed topography products from the smoothed DEM data, are subject to both random and systematic errors. Here, we estimate a random error of $5 \mathrm{~m}(1-\sigma)$ for the filtered surface elevation transects. Systematic errors arise from bed

10 topography and vary spatially across the ice sheet, but average $70 \mathrm{~m}$ along the sampled flux gates.

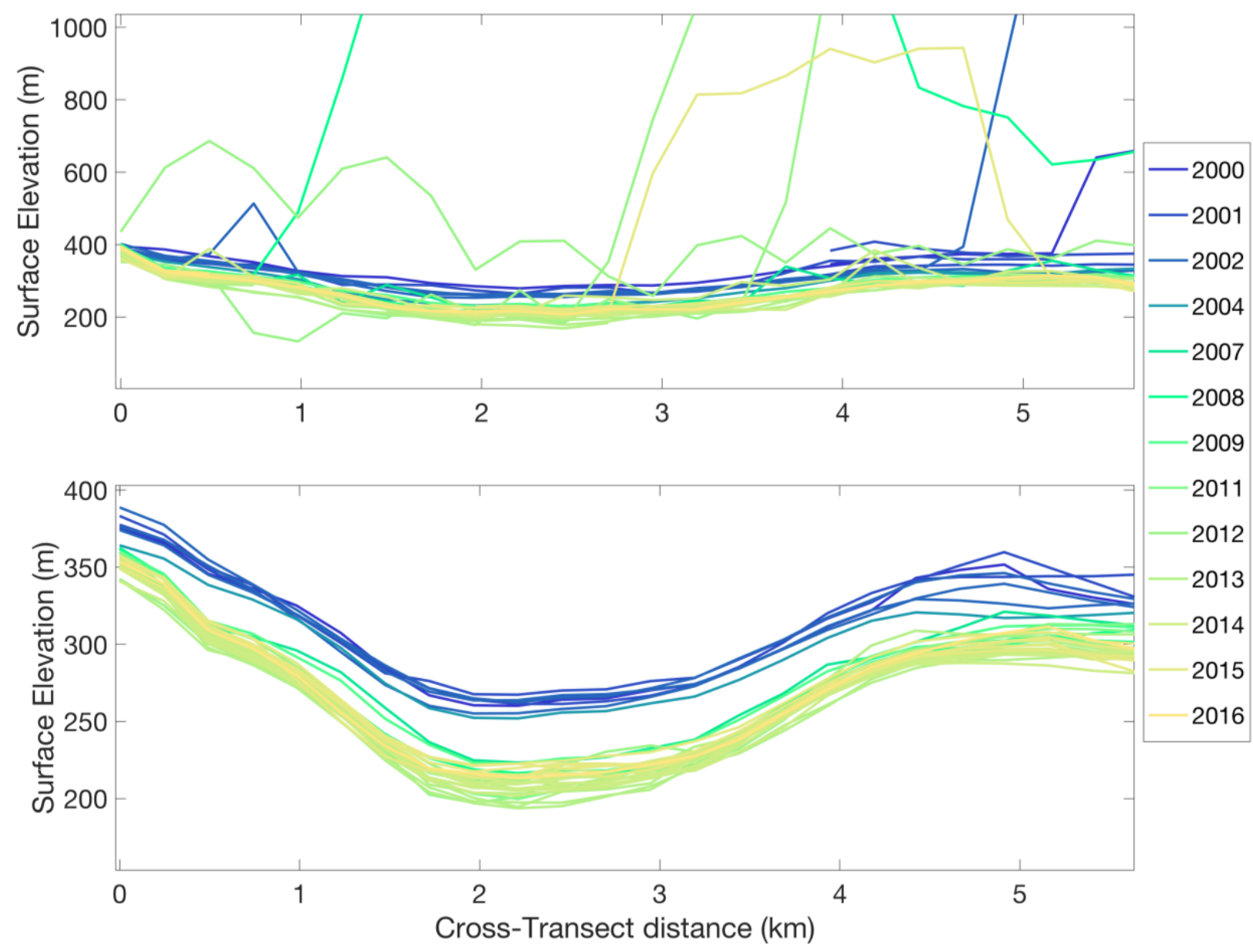

Figure S2: An example of the post-processed surface elevation values (bottom panel) compared to raw data (top panel) across the glacier flux gate transect at Kangia Glacier. 


\section{S.4 Derivation of Continuous Discharge Time Series}

The continuous glacier velocity time series, now comprised of a combination of modeled and observational data, is of a higher temporal resolution than available ice thickness data. For this reason, observations of ice thickness $(h)$ are linearly interpolated onto the temporal space $\left(t_{i}\right)$ of glacier velocity $(v)$ observations. A record of solid ice discharge at each glacier,

5 Eq. (S4), is then calculated by summing the discharge at each equally-spaced bin $(j)$, with width $w$, along the glacier flux gate. A constant density $(\rho)$ of $910 \mathrm{~kg} \mathrm{~m}^{-3}$ is assumed with depth.

$D_{t_{i}}=\sum_{j=1}^{n} h_{j, t_{i}} w_{j} \vec{v}_{j, t_{i}} \rho$

10 Equation S4

Error in discharge estimates therefore arise from errors in glacier thickness (he) and velocity (ve) retrievals, where ve represents the summed quadrature of the $\mathrm{u}$ and $\mathrm{v}$ components of displacement. Total discharge error $(D E$, hereafter to be expressed as 1 standard deviation, $\sigma$ ), is the sum of random (denoted by subscript $r$ ) and systematic errors (denoted by

15 subscript $s$ ). Random error, Eq. (S5), at each time step is found by summing the errors introduced by both glacier velocities and random errors in ice thickness:

$D E_{r, t_{i}}=\sum_{j=1}^{n} h_{j, t_{i}} w_{j} \overrightarrow{v e}_{j, t_{i}} \rho+\sqrt{\sum_{j=1}^{n}\left(h e_{r, j, t_{i}} w_{j} \vec{v}_{j, t_{i}} \rho\right)^{2}}$

\section{Equation S5}

20 Systematic errors are a result of biases in bed topography retrievals, and are calculated as:

$D E_{s, t_{i}}=\sum_{j=1}^{n} h e_{s, j, t_{i}} w_{j} \vec{v}_{j, t_{i}} \rho$

\section{Equation S6}

The discharge time series now include weekly estimates of $D$ for periods when data is available, and monthly modeled

25 estimates for periods of missing data. A Monte Carlo Ensemble is performed for each glacier time series to derive the continuous discharge curve, which can be sampled at equally-spaced intervals. Using the existing estimates of $D$ and $D E$, a cubic smoothing spline is fit to the time series. The splines are piecewise cubic functions with continuous first and second 
derivatives, and are often used to estimate continuous, stochastic processes. For this reason, they are a tool commonly used in climate science (Jones et al. 2015) and can have applications in modelling glaciological process (Krimmel and Rasmussen, 1985; Horgan et al. 2015). A smoothing parameter controls how closely the spline is constrained to observations. The smoothing parameter is determined empirically for each glacier, and typically falls within the range of

5 0.001-0.005. Smoothing parameter selection is done with consideration given to accommodate the magnitude of individual estimate errors, notable trends, and the time series variance while avoiding overfitting the series. Common problems with spline fits, such as "overshooting" that can arise due to temporal gaps, are largely avoided due to the completeness and semiuniform spacing of estimates throughout the time series. The described spline fit is repeated for 1000 iterations at each glacier, where during each iteration the function is fit to a new set of perturbed observations, generated by adding normally-

10 distributed random errors sampled from the observational uncertainty, $D E$. Large individual errors therefore result in a segment of the time series where the spline is less constrained. Lastly, continuous mean estimates of $D$ and the standard deviation, $\sigma$, of solutions at each time step are calculated from the 1000-member ensemble (Figure S3). A small subset of glacier time series contains only annually, rather than seasonally, resolved $D$ due to a sparsity of precise velocity observations. This subset includes smaller glaciers mostly along near the central eastern margin and the four northernmost

15 glaciers (Steensby, C.H. Ostenfeld, Academy, and Hagen Brae), and altogether typically contributes $<10 \mathrm{Gta}^{-1}$ to the GrISwide total. 

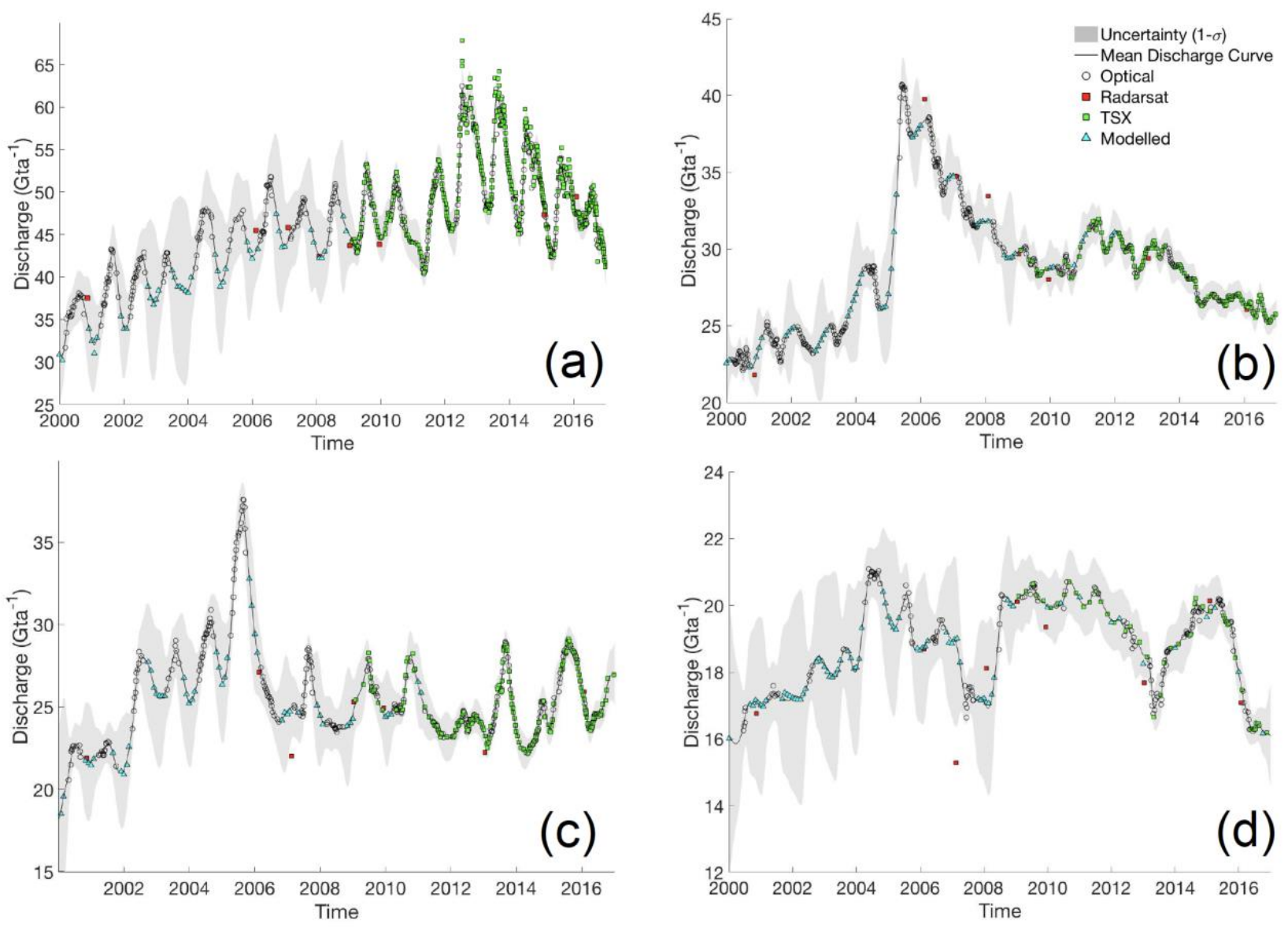

Figure S3: Select solid ice discharge time series for four of GrIS's largest glaciers: Jakobshavn Isbrae (a), Kangerdlugssuaq (b), Helheim (c), and the central arm of Køge Bugt glacier (d). The series show the resulting continuous time series curve (black), with discharge estimates derived from optical observations, TerraSAR-X, RADARSAT -1 and -2 , and modeled estimates. Shading represents uncertainty $(1-\sigma)$.

\section{S.5 Validation}

Wintertime observations of glacier velocity are available from RADARSAT -1 and -2 (Joughin et al., 2015) for select years of the study. These velocity mosaic products represent the average ice velocity over multi-month periods and are thus not directly appropriate as single point observations for sub-seasonal time series reconstructions. However, these data can

10 serve as an important independent source to validate individual discharge time series. The four mosaics available prior to 2009, and the advent of Terra/TandemSAR-X observations, are particularly useful because they serve as the only existing near ice-sheet wide wintertime velocity observations. Discharge calculated from RADARSAT velocity observations are compared to the derived continuous discharge curves described above by integrating the curves over the individual RADARSAT observational periods. For example, to compare the derived solutions to RADARSAT estimates of $D$ using the 
2005/2006 winter velocity mosaic, the total cumulative discharge would be calculated by integrating the values along the curve over the time interval extending from 13 December 2005 through 20 April 2006, corresponding to the observational period of the RADARSAT 2005/2006 campaign. Because RADARSAT observations represent a multi-month average, we assume a constant velocity over the same interval when calculating the radar-derived cumulative discharge. This validation

5 is performed at each glacier for each available RADARSAT mosaic. The wintertime derived discharge estimates are consistent within margins of error with discharge calculated from wintertime RADARSAT observations for $91 \%$ of occurrences. This level of agreement allows for a high degree of confidence in the magnitude of the derived wintertime discharge estimates, which are often the periods that relied most heavily on modeled estimates in lieu of available shortbaseline observations.

\section{0-2008}

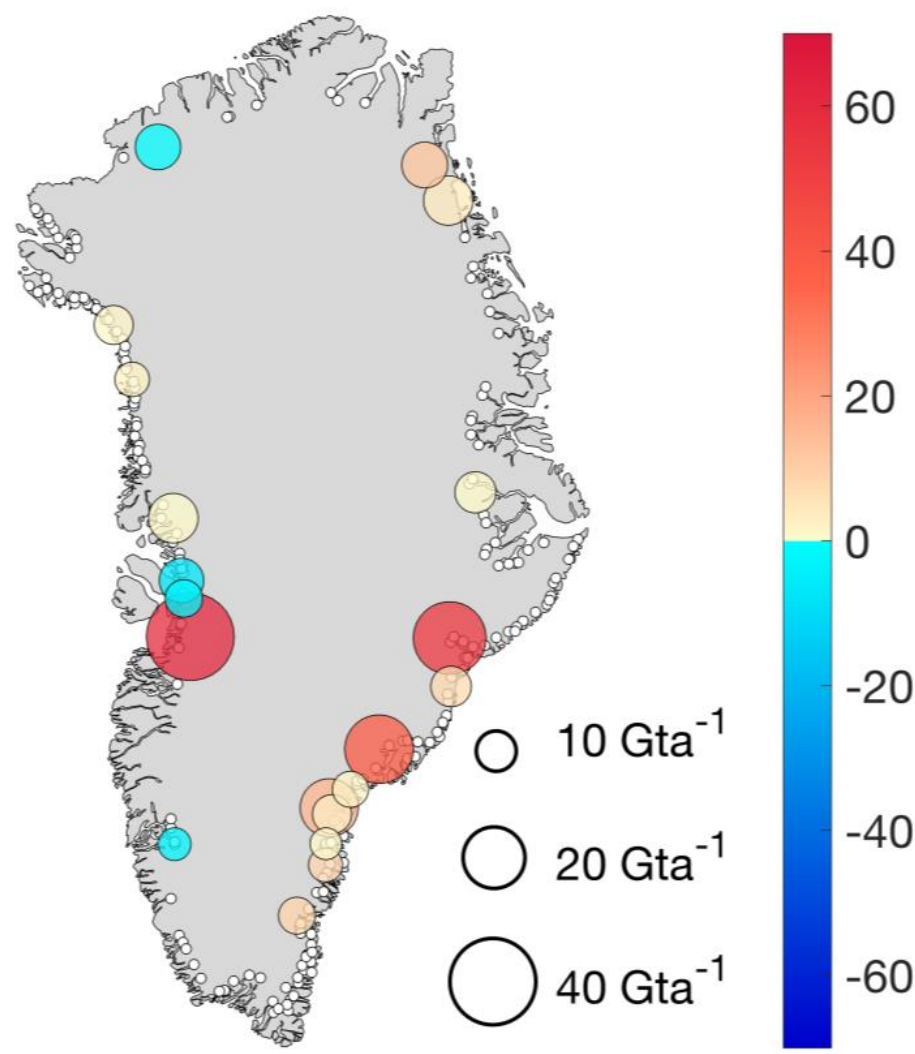

2008-2016

Figure S4: Spatial distribution of all surveyed glaciers, denoted by a white marker near the flux gate of each glacier. The 20 largest glaciers are shown by colored markers, with the marker size corresponding to the average $D$ over both the $2000-2008$ period (left) and 2008-2016 period (right). The color of the markers shows the total $D$ anomaly (in $\mathrm{Gta}^{-1}$ ) relative to the reference years 2000 (left) and 2008 (right). Positive discharge anomalies indicate increased $D$ relative to the reference years. 


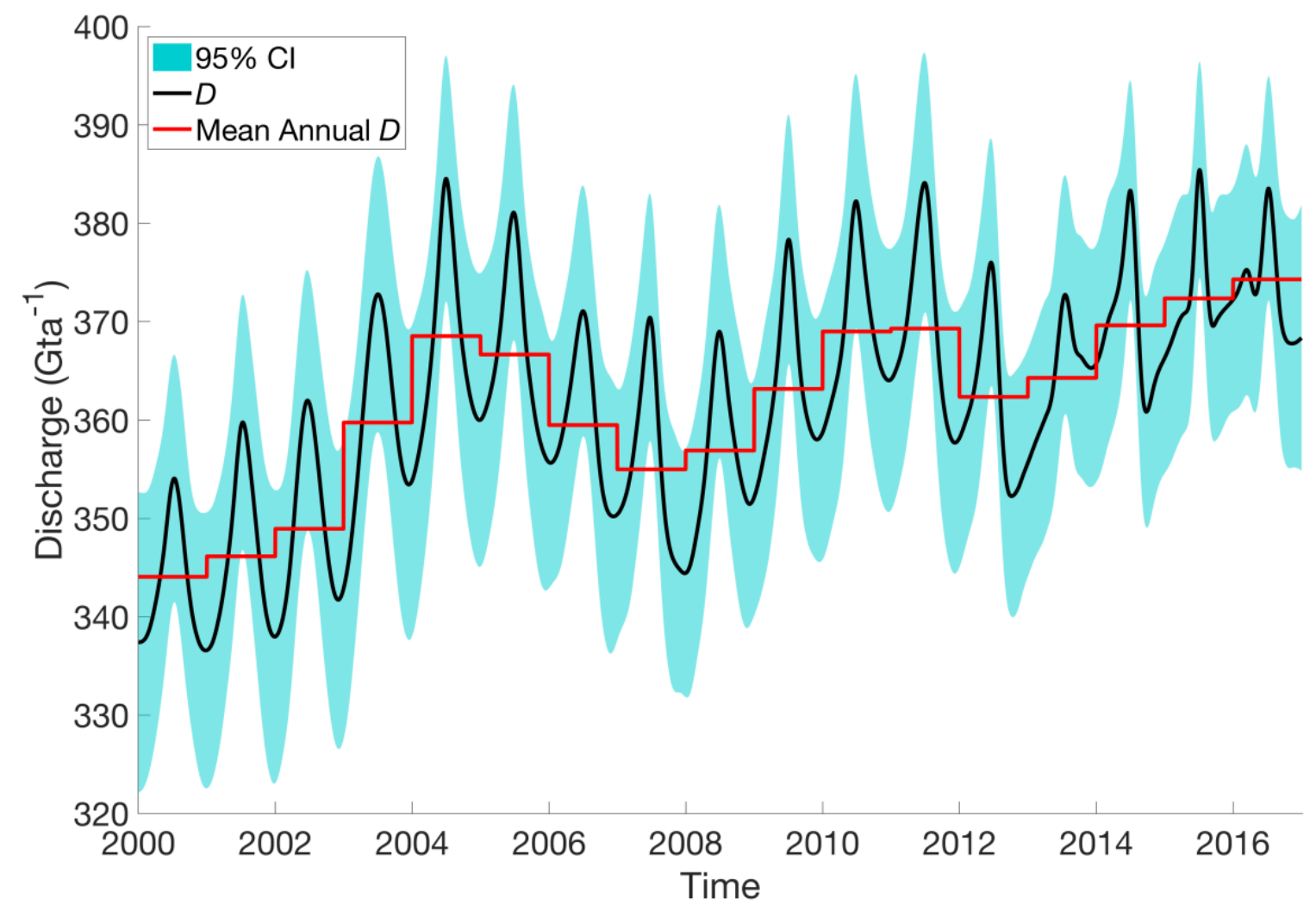

Figure S5: Net dynamic discharge, $D_{s}$, for the GrIS excluding the four largest glaciers: Jakobshavn, Kangerdlugssuaq, Helheim, 5 and the central branch of Køge Bugt. The red line displays the annually averaged $D_{s}$. 

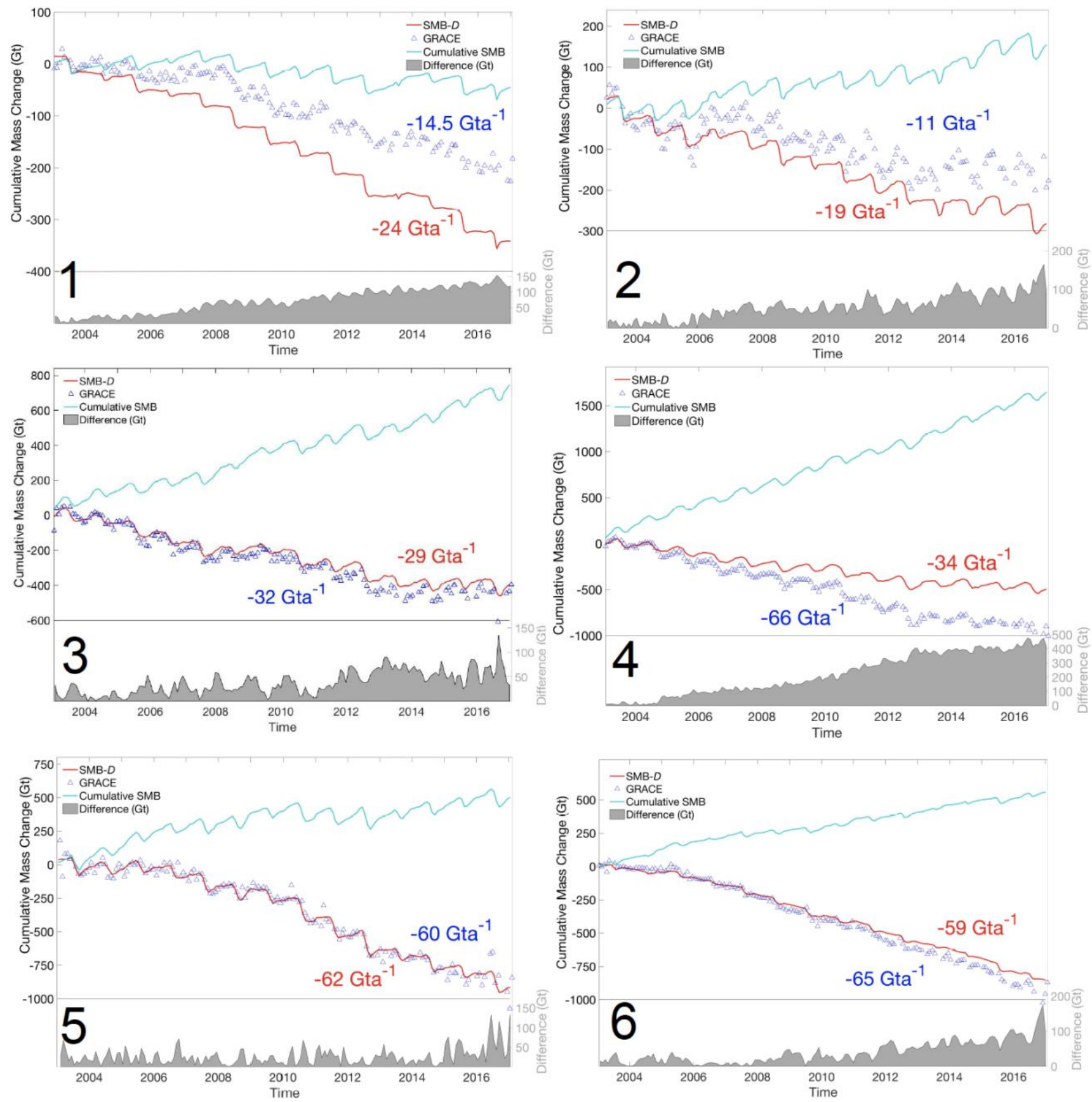

Figure S6: Comparative cumulative mass change relative to 2003 between GRACE, and monthly SMB $-D$ for each of the six GRACE sub-basins, delineated in Figure S6. Cumulative SMB is also plotted, with cumulative differences between estimates plotted in the lower panel, associated with the right $y$-axis. 


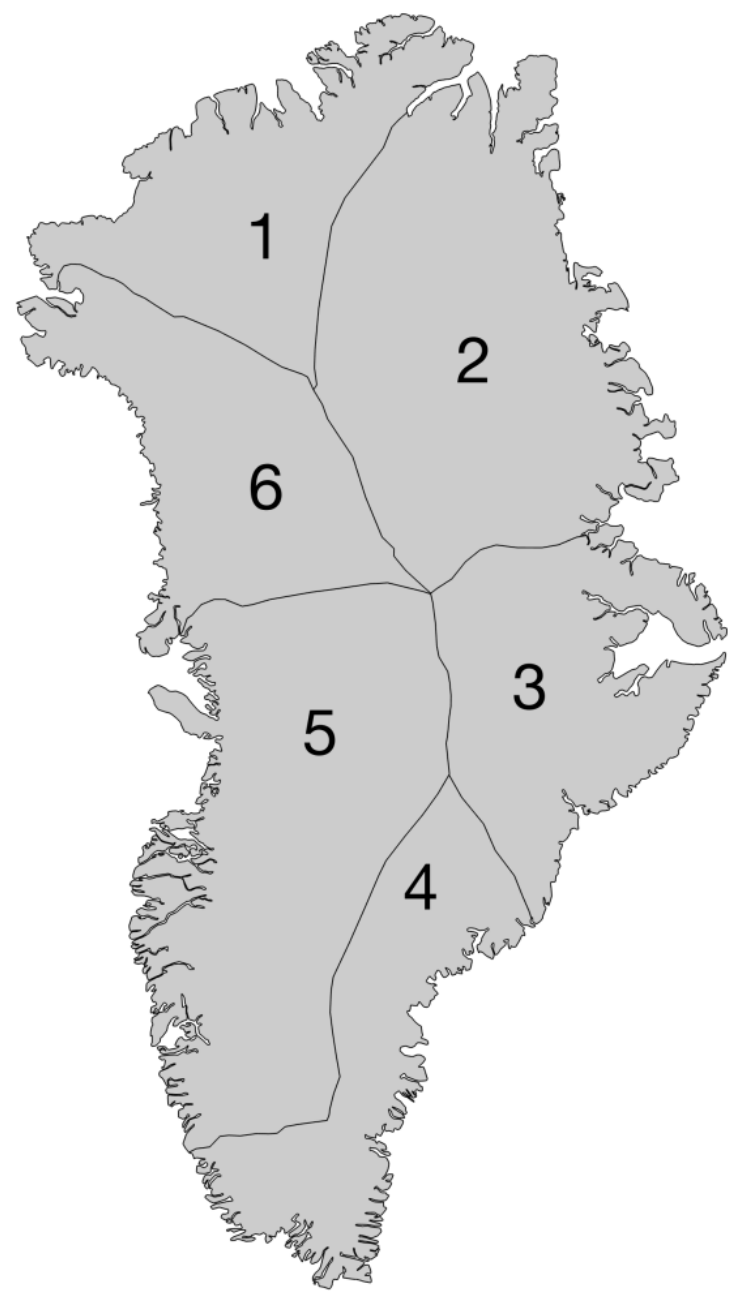

Figure S7: Regional boundaries used in basin-scale SMB -D to GRACE comparisons. 


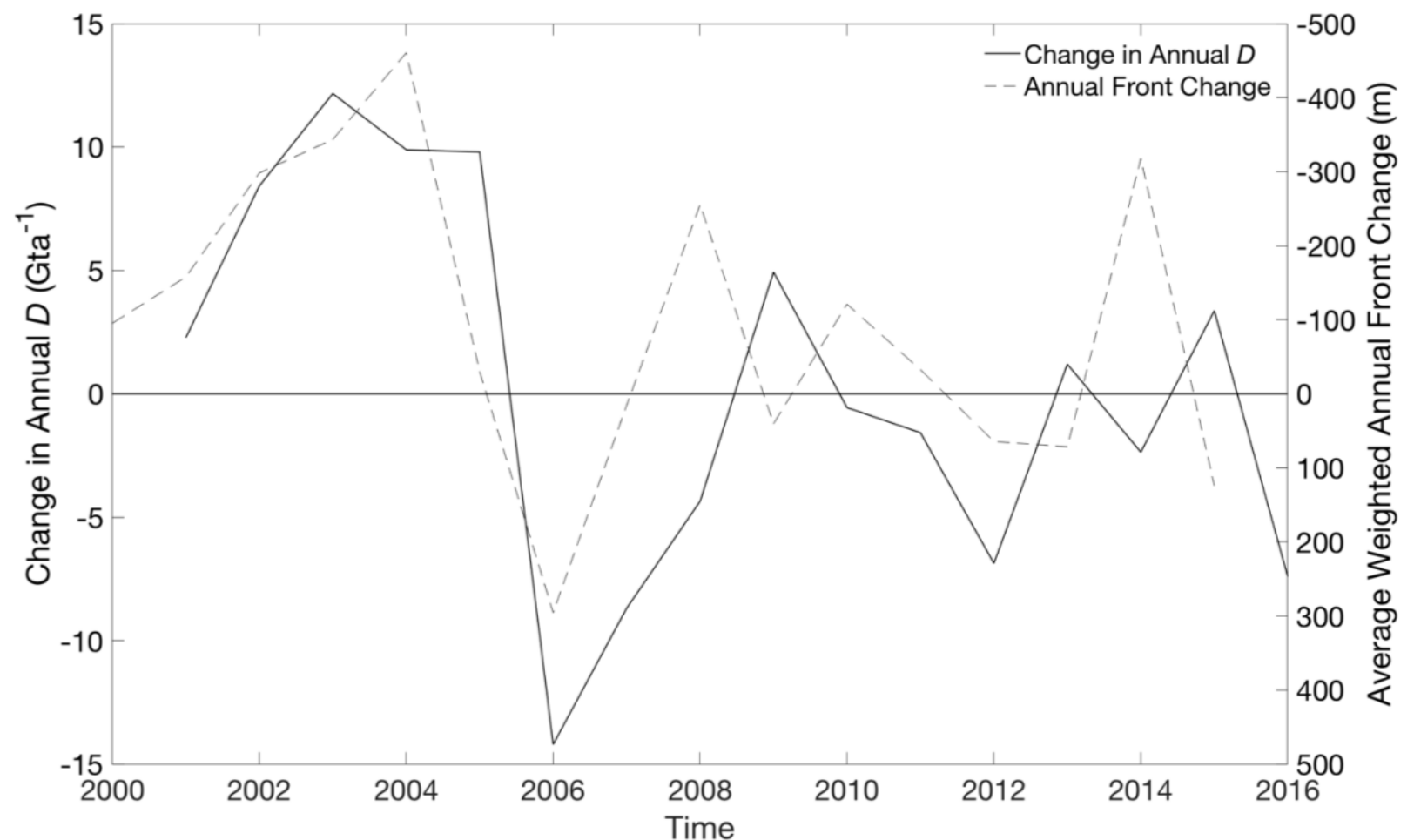

Figure S8: Change in annual $D$ (defined as the difference between the current and previous year's $D$ ) in the SE region, and the annual weighted regional front change in meters (right axis). The axis associated with front change is reversed, with negative front 5 change values indicating retreat. 


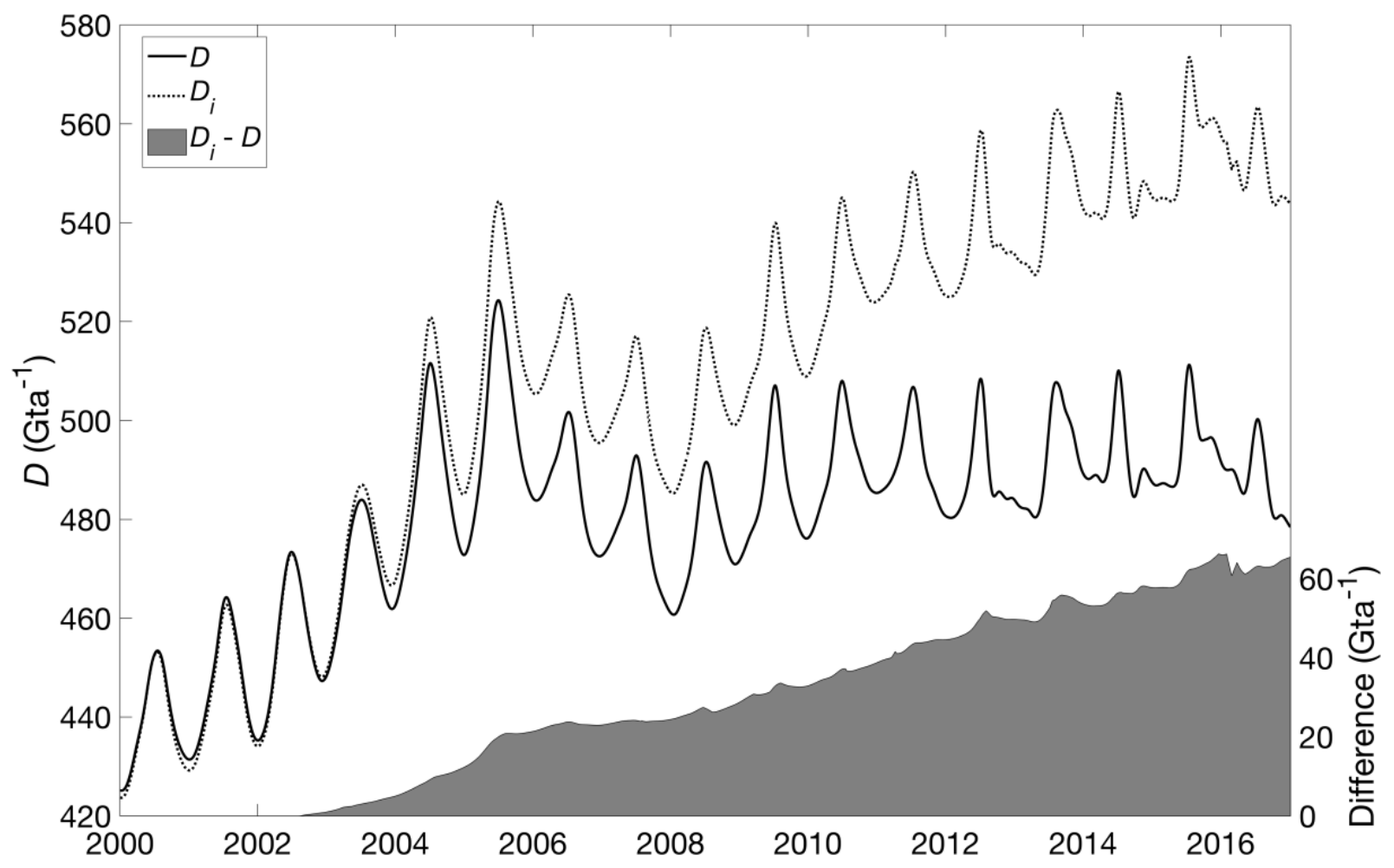

Figure S9: Net GrIS $D$ (solid black) for the GrIS for the 2000-2016 study period, with discharge scaled to remove the effect of thinning, $D_{i}$, plotted by the dotted line. Differences between the original and scaled estimates $\left(D_{i},-D\right)$ through time are shaded in gray (right axis). 

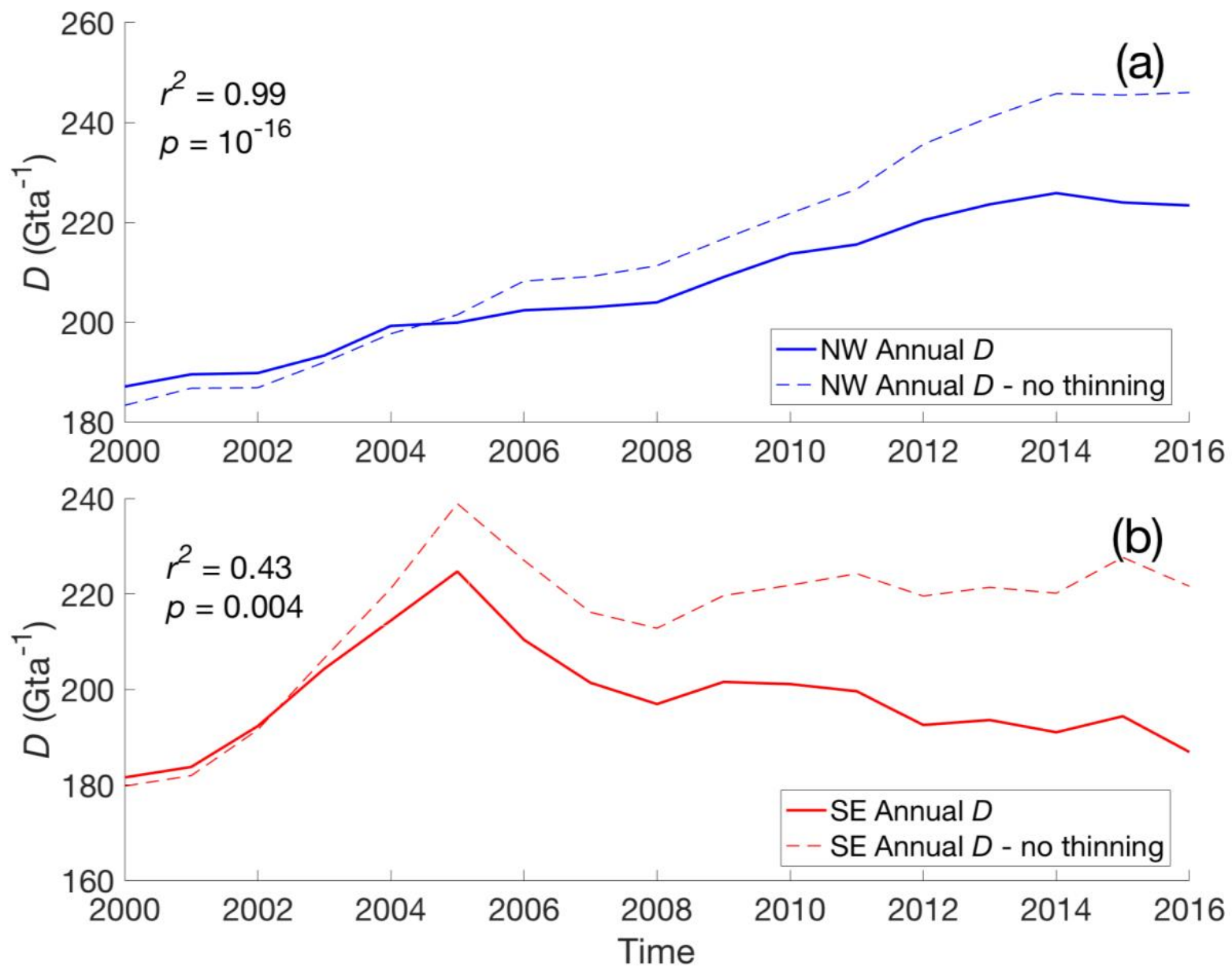

Figure S10: Annual $D$ and Annual $D_{i}$ (scaled to remove the effect of thinning) in the NW region (a), and in the SE region (b). Text 5 describes linear correlation and correlation significance between the raw and scaled time series. 


\section{References}

Horgan, H. J., Anderson, B., Alley, R. B., Chamberlain, C. J., Dykes, R., Kehrl, L. M. and Townend, J.: Glacier velocity variability due to rain-induced sliding and cavity formation, Earth Planet. Sci. Lett., 432, 273-282, doi:10.1016/j.epsl.2015.10.016, 2015.

Howat, I. M., Negrete, A. and Smith, B. E.: The Greenland Ice Mapping Project (GIMP) land classification and surface elevation data sets, Cryosphere, doi:10.5194/tc-8-1509-2014, 2014.

Jeong, S., Howat, I. M. and Ahn, Y.: Improved Multiple Matching Method for Observed Glacier Motion with Repeat Image

10 Feature Tracking, IEEE Trans. Geosci. Remote Sens., 55, 2431-2441, 2017.

Jones, S. D., Le Quéré, C., Rödenbeck, C., Manning, A. C. and Olsen, A.: A statistical gap-filling method to interpolate global monthly surface ocean carbon dioxide data, J. Adv. Model. Earth Syst., 7(4), 1554-1575, doi:10.1002/2014MS000416, 2015.

15

Joughin, I., B. Smith, B., Howat, I., and Scambos, T.: MEaSUREs Greenland Ice Sheet Velocity Map from InSAR Data, Version 2. Boulder, Colorado USA. NASA National Snow and Ice Data Center Distributed Active Archive Center, 2015, updated 2017.

20 Korona, J., Berthier, E., Bernard, M., Rémy, F. and Thouvenot, E.: SPIRIT. SPOT 5 stereoscopic survey of Polar Ice: Reference Images and Topographies during the fourth International Polar Year (2007-2009), ISPRS J. Photogramm. Remote Sens., 64(2), 204-212, doi.org/10.1016/j.isprsjprs.2008.10.005, 2009.

Krimmel, R. and Rasmussen, L.: Using sequential photography to estimate ice velocity at the terminus of Columbia Glacier, 25 Alaska, Ann. Glaciol., 117-123, 1985.

Morlighem, M., Williams, C. N., Rignot, E., An, L., Arndt, J. E., Bamber, J. L., Catania, G., Chauché, N., Dowdeswell, J. A., Dorschel, B., Fenty, I., Hogan, K., Howat, I., Hubbard, A., Jakobsson, M., Jordan, T. M., Kjeldsen, K. K., Millan, R., Mayer, L., Mouginot, J., Noël, B. P. Y., O’Cofaigh, C., Palmer, S., Rysgaard, S., Seroussi, H., Siegert, M. J., Slabon, P., 30 Straneo, F., van den Broeke, M. R., Weinrebe, W., Wood, M. and Zinglersen, K. B.: BedMachine v3: Complete Bed Topography and Ocean Bathymetry Mapping of Greenland From Multibeam Echo Sounding Combined With Mass Conservation, Geophys. Res. Lett., 44, 11,051-11,061, doi:10.1002/2017GL074954, 2017. 
Nguyen, A. T. and Herring, T. A.: Analysis of ICESat data using Kalman filter and kriging to study height changes in East Antarctica, Geophys. Res. Lett., 32, 4-7, doi:10.1029/2005GL024272, 2005.

Pritchard, H. D., Arthern, R. J., Vaughan, D. G. and Edwards, L. A.: Extensive dynamic thinning on the margins of the 5 Greenland and Antarctic ice sheets, Nature, 461, 971, https:// doi.org/10.1038/nature08471, 2009. 